\title{
Corrigendum
}

\section{Corrigendum to "Unilateral Giant Hydronephrosis Secondary to Ureteropelvic Junction Obstruction in a Middle-Aged Woman"}

\author{
Masresha S. Dino, ${ }^{1}$ Seid Mohammed Hassen $\mathbb{D D}^{1},{ }^{1}$ and Tesfaye H. Tufax ${ }^{2}$ \\ ${ }^{1}$ Department of Surgery, Urology Unit, Addis Ababa, St. Paul's Hospital Millennium Medical College, Ethiopia \\ ${ }^{2}$ Department of Obstetrics and Gynecology, St. Paul's Hospital Millennium Medical College, Addis Ababa, Ethiopia \\ Correspondence should be addressed to Masresha S. Dino; masreshasolomon412@gmail.com
}

Received 26 January 2022; Accepted 26 January 2022; Published 2 March 2022

Copyright (c) 2022 Masresha S. Dino et al. This is an open access article distributed under the Creative Commons Attribution License, which permits unrestricted use, distribution, and reproduction in any medium, provided the original work is properly cited.

In the article titled "Unilateral Giant Hydronephrosis Secondary to Ureteropelvic Junction Obstruction in a MiddleAged Woman" [1], the email address of the co-author Seid M. Hassen needs to be changed. This was a mistake on the authors' behalf, and the correct email address is as follows: from "seid96@yahoo.com" to "seidm96@yahoo.com."

\section{References}

[1] M. S. Dino, S. M. Hassen, and T. H. Tufax, "Unilateral giant hydronephrosis secondary to ureteropelvic junction obstruction in a middle-aged woman," Case Reports in Urology, vol. 2021, Article ID 9900560, 4 pages, 2021. 